\title{
Current and future trends in men's health clinics
}

\author{
Justin J. Houman, Sriram V. Eleswarapu, Jesse N. Mills \\ Department of Urology, David Geffen School of Medicine, University of California, Los Angeles, CA, USA \\ Contributions: (I) Conception and design: All authors; (II) Administrative support: All authors; (III) Provision of study material or patients: All authors; \\ (IV) Collection and assembly of data: All authors; (V) Data analysis and interpretation: All authors; (VI) Manuscript writing: All authors; (VII) Final \\ approval of manuscript: All authors. \\ Correspondence to: Jesse N. Mills, MD. Health Sciences Associate Clinical Professor, Department of Urology, David Geffen School of Medicine, \\ University of California, 10945 Le Conte Ave., Ueberroth \#3361, Los Angeles, CA 90095, USA. Email: jnmills@mednet.ucla.edu.
}

\begin{abstract}
Men's health is a unique field that requires a multi-disciplinary approach to appropriately treat the full spectrum of men's health needs. Given that interest in men's health is relatively new, the definition of a men's health clinic continues to evolve. Originally conceived as testosterone replacement centers, men's health clinics are increasingly understood to encompass male endocrine, surgical, urologic, physical performance, and psychological issues. As interest in men's health continues to grow, it is important to focus on the field's future, including pharmacies, telemedicine, and the diffusion of healthcare.
\end{abstract}

Keywords: Men's health; future; current

Submitted May 01, 2019. Accepted for publication Aug 16, 2019.

doi: $10.21037 /$ tau.2019.08.33

View this article at: http://dx.doi.org/10.21037/tau.2019.08.33

\section{Introduction}

Historically, there has been very little interest in what is now understood as "men's health". This is in spite of the notable gender differences in health outcomes. In the United States, male life expectancy at birth (76.4 years) is on average 4.8 years lower than female life expectancy (81.2 years) (1). Men in the United States continue to present with higher lifetime risks for heart disease, cancer, diabetes, HIV/AIDS, suicide, liver disease, and additional morbidities than women (2). These gender differences in disease prevalence and life expectancy are not unique to the United States (3). This is perpetuated by the fact that men have had a general reluctance to seek help from physicians and other health care practitioners when it comes to their own health. Men are less likely than women to be aware of disease symptoms, and men use primary care services less frequently than women (4). This is particularly relevant to mental health, since men experience suicide rates nearly 4 times higher than women, though men suffer from depression at lower rates (5).

In 1984, Professor Louis Ignarro's discovery that the properties of nitric oxide were identical to those observed with endothelium-derived relaxing factor ultimately led to the development of sildenafil (6). It was not until 1999, when sildenafil became commercially available as Viagra, that the media began giving extensive coverage to an exclusively male health condition, erectile dysfunction (ED). Later, media attention to ED surged after emerging data indicated that ED in young men is associated with a marked increase in the risk of future cardiac events (7). This opened the floodgates to the discussion of other related issues like male intimacy, depression, heart disease, prostate cancer, diabetes_or collectively "men's health".

This interest in men's health was flung further into the international spotlight by the "Movember" movement. In 2006, the Movember Foundation was established as a global charity with participants in Australia and New Zealand (8). Since then, it has become an annual event heralded by the growing of mustaches during the month of November to raise awareness of men's health issues like cancer, testicular cancer, and men's suicide. With the aim to "change the face of men's health", the Movember Foundation raised $\$ 88,000,000$ AUD (\$63,000,000 USD) towards men's healthrelated causes (8). Furthermore, the establishment of June as Men's Health Month and September as National Prostate Cancer Awareness Month have reinforced the importance 
of men's health-related issues to the general public.

With an increased awareness and interest of men's health issues, it is important to continue to focus resources towards improving health outcomes for men around the world. The purpose of this review is to provide a contemporary understanding of what constitutes a men's health clinic and describe the future advancements that will take place in this field as they pertain to sexual and reproductive health.

\section{What is a men's health clinic?}

There exists a dichotomy in the world of men's health not seen in other specialties. Academic medical centers have recently embraced men's health more fervently over the last decade. This may be in part due to the gradual decline in prostate cancer screening by primary care physicians (PCPs) (9) and the subsequent lack of access to men through a typical, screening-based primary care pipeline. Moreover, there is also a heightened interest in male urologic health with the advent of new treatment options for hypogonadism, Peyronie's disease, and ED. Because of the early lack of traditional medical clinics embracing a men's health platform, and because there is money to be made, cash-based men's health clinics have popped up across the country in free-standing centers, strip mall outlets, and other non-traditional medical office sites. The building block and premise of the clinic is to optimize men's health through testosterone and supplement therapy. Most of these free-standing centers are not staffed by urologists, cardiologists, or other health care professionals with academic training in male endocrinology, sexual medicine, or preventative medicine. Instead of offering a traditional medical office visit with history-taking, physical exam, or appropriate lab and imaging studies, these clinics offer memberships with frequent testosterone injections and lab monitoring.

Since the early 2000s, treatments for low testosterone, or "low T", have been gaining popularity. From 2001 to 2011, testosterone use in the United States tripled, and hundreds of testosterone clinics emerged to capitalize on this trend (10). During the same period, total testosterone sales increased 12 -fold globally, rising from $\$ 150$ million in 2000 to $\$ 1.8$ billion in 2011 (10). Total testosterone use among men over 30 increased from $0.52 \%$ in 2002 to $3.20 \%$ in 2013 .

These "low T" for-profit clinics represented the original men's health clinics, providing patients with various forms of testosterone replacement therapy, often without a clear indication (11). For example, the Low T Center, headquartered in Texas, states that they will treat any man aged 25 or older with a testosterone level of $350 \mathrm{ng} / \mathrm{dL}$ or lower. As part of their membership plan, patients can receive all the necessary office visits, lab work, and injection therapy for $\$ 395$ per month or $\$ 750$ for 3 months (12). In comparison, a similar office visit with a urologist currently costs roughly $\$ 800$. However, these centers generally only offer patients injection therapy, which provides patients with a sudden, feel-good rush, making the next injection more appealing. The main concern with centers that monetize testosterone therapy is whether they are accurately making a diagnosis, listening to all of a patient's symptoms, and properly tailoring treatment regimens. Rather than assessing symptoms, these clinics may be more inclined to market testosterone replacement due to financial incentives. Furthermore, patients receiving testosterone therapy need close monitoring due to the risks associated with elevated T levels; however, clinics with membership models lack the rigorous follow-up protocol typically offered in a traditional physician's office. While there is a compelling marketing drive for nontraditional men's clinics that merely peddle testosterone and penile injection therapy, there is certainly a missed opportunity to evaluate men in further detail. Rarely do these centers discuss the prostate cancer risk or fertility implications of testosterone replacement, for example.

Throughout the last decade, what has defined a men's health clinic has evolved to encompass more than just testosterone and can include urologic issues, ED, testosterone replacement, sleep medicine, mental health, addiction health, cardiology, dermatology, and hair loss. As a result, academic centers, which have the multi-disciplinary team to address the wide variety of men's health needs, began to establish men's health clinics as well. Academic centers are now providing a comprehensive approach to men's health, with physicians who are comfortable managing male endocrine, sexual, reproductive, surgical, physical performance, and psychological issues. In addition, various academic urology programs are now offering fellowship training in men's health, covering sexual dysfunction, infertility, and andrology. The need for more men's health experts is evidenced by the growth in the number of urology fellowship training programs available, having grown from 8 to 19 within the last decade.

\section{What is the future of men's health clinics}

\section{Pharmacies}

As oral PDE-5 inhibitors such as Cialis and Viagra are 
widely utilized to treat $\mathrm{ED}$, cost remains prohibitive for some patients with ED. Some patients have turned to herbal remedies as a way to alleviate ED symptoms. Most of these herbs have no human studies supporting their use in humans; however, Panax ginseng and Butea superb have some evidence of improved erectile function in humans, however the data have not yet been reproduced (13). There needs to be significantly more research about the role of herbal remedies in the treatment of ED. as it is an unregulated market which could lead to significant side effects associated with them (14). While current ED medications remain expensive, pharmacies could start providing men with lowcost alternatives to these expensive medications through compounding medications. Compounding medications have been available for years with an efficacy and tolerability similar to brand-name medications (15). The future of men's health includes compounding pharmacies delving into the world of ED medications, offering patients with affordable, effective treatments for ED.

\section{Telemedicine}

The telemedicine industry is projected to be a $\$ 48.8$-billiondollar market by the year 2023 (16). Telemedicine is finding increased usage within hospitals, private physician offices, home health agencies, and nursing facilities (17). In the United States alone there were 100,000 telemedicine consults performed each month in 2015 (18). Telemedicine is opening the door to the possibility of having personalized healthcare exclusively available at touch of a button. As telemedicine continues to expand, its role in urology and men's health continues to be felt.

A recent report by Accenture looked at current healthcare consumer patterns and found that only $55 \%$ of Generation $Z$ patients have a PCP (19). This is in contrast to past generations, which had rates as high as $84 \%$ for PCP coverage (19). This trend suggests that Generation Z patients, and future generations yet to come, are looking to address their medical needs without utilizing a PCP, as has been the standard model for healthcare delivery in years past.

Healthcare sectors that had previously been primary reliant on face-to-face consultations are beginning to shift towards telemedicine. New companies such as Hims and Roman Health are utilizing telemedicine to address ED. Both companies are offering online prescriptions for common ED medications without the need to see a PCP (20). The Keeps company is utilizing telemedicine in a similar fashion to provide hair loss treatment to patients. However, when utilizing these websites, patients are only required to complete a short questionnaire, as physical exams are not necessary, nor are informed consent discussions on the long-term risks associated with medications such as finasteride. Moreover, although ED is one of the early signs of cardiovascular disease, these online platforms omit the work-up of cardiovascular risk factors. The federal drug market rules only apply to drug manufacturers and drug distributors, not online prescription drug services such Hims and Roman Health. Since there is no state or federal agency overseeing these consumer drug websites, they do not have to comply with the same standards as drug distributors. These lax marketing regulations may compromise patient care.

While approximately $50 \%$ of men will experience some form of ED (21), only approximately $25 \%$ actively seek consultation (22). This discrepancy is partially due to the social stigma in society surrounding men's open discussion of ED, preventing men from confiding with healthcare professionals and obtaining the help that they need (23). This is exactly the area of healthcare that telemedicine seeks to address. By providing personalized care to patients within the privacy of a patient's home, telemedicine companies are able to deliver healthcare services to patients seeking consultations regarding topics that had previously been considered too shameful to address in a public space. These services provide patients with a simple and convenient alternative to seeing a PCP for their common healthcare needs. After a telemedicine "visit" with a doctor, the patient is prescribed medication that can then be purchased directly through the telehealth platform, all within the comfort of a patient's home.

The main driving force for the exponential growth of online doctoring is generic sildenafil. Retail pricing of $100 \mathrm{mg}$ Viagra prior to its generic $20 \mathrm{mg}$ sildenafil dosing for pulmonary hypertension hovered around 30 to 50 USD per pill. Patients can now find hundreds of pharmacies selling $20 \mathrm{mg}$ dosing for around 1 USD a pill. This business model practically built itself, offering a relatively safe drug in high demand through an online, discreet visit with same day service. Since traditional medical clinics rarely offer same day servicing, the instant gratification of signing on to an online physician and getting the little blue pill delivered right to one's doorstep is irresistible to the average male. Few data exist so far to suggest that this is a harmful way to handle men's health concerns. Academic specialists have voiced concerns that telemedicine may underdiagnose certain pathologies $(24,25)$. In our experience at the Men's 
Clinic at University of California, Los Angeles (UCLA), we have found comorbid pathology on physical exam, blood tests, semen analysis, or imaging findings in over $30 \%$ of men under 40 years of age in an almost 400-man database presenting with ED. Our data provide evidence that an inperson visit with a physician has a value-added role over telehealth visits with a "pill mill".

\section{Future of male contraception}

When it comes to male contraception, current options include condoms, which occasionally fail and are incorrectly used at times, and vasectomy, which is considered a form of permanent sterilization. Women, on the other hand, have many more options, including pills, patches, rings, injections, intrauterine devices, and surgery-thus creating an unequal playing field between the genders. In recent years, however, there have been some promising advances in male birth control, soon to provide men with more options than simply condoms or vasectomies.

Currently, there are two delivery methods under active investigation, a male hormonal contraceptive in the form of a pill and an injection (26). Recently, researchers discovered that dimethandrolone undecanoate (DMAU) effectively reduced LH and FSH levels, thus impairing spermatogenesis (27). DMAU is converted to dimethandrolone, which binds to androgen receptors, thus suppressing gonadotropin release and, as a result, inhibiting spermatogenesis. However, serum testosterone levels for all men who received DMAU were in the hypogonadal range, resulting in complaints of decreased libido and newonset acne. Although still in clinical trials, an oral male contraceptive pill is on the horizon, likely within the next decade, as current versions have been shown to be both safe and effective (27).

\section{Current state of men's health centers}

Although men's health clinics are a new phenomenon, the pathology is not, so there are currently established clinics and physicians who are treating men's health needs. Hundreds of ED clinics exist, which provide men with a variety of ED treatment options, including low intensity shock wave lithotripsy (LISWT), intracavernosal injections, platelet rich plasma injections, and testosterone therapy. However, patients in these for-profit clinics are being offered a small selection of the available therapies for ED since many of them are staffed primarily by nurse practitioners or physician assistants. Few of these clinics have a urologist managing these patients, and patients are not offered all the ED treatment options, including vacuum erection devices, intraurethral suppositories, and penile prostheses. Furthermore, since some of these clinics do not have a staff urologist, management of complications associated with these therapies could be problematic. Additionally, for profit men's clinics rarely address preventative medicine and most treatments offer symptomatic relief rather than teaching lifestyle modification, health screening, and addressing underlying issues of ED such as cardiovascular disease.

\section{"March Madness" vasectomy}

In 2004, a community urologist tried to promote vasectomies during March Madness. As media outlets and news sources began publishing the story, it gained nationwide popularity and became a men's health phenomenon. A recent study examined vasectomy trends in the US and found that the month of March and end of the year are when the most number of vasectomies are performed (28). The "March Madness Vasectomy", as it has come to be known, is tied to an increase in men getting vasectomies during the March Madness NCAA basketball tournament. Typically, men are recommended to limit strenuous activity and apply ice to the affected area postprocedure. This recovery protocol allows men to bingewatch basketball games all weekend.

As urologists have tried to associate March Madness with vasectomies through various promotional slogans such as "U Vas Madness" and "it's hip to get snipped", vasectomies are now being linked to other sports' weekend tournaments. The Friday of the professional golf Master's tournament is now becoming a popular day for vasectomies, giving men the chance to watch one of the golf season's most important tournaments all weekend while recovering. The future of men's health includes providing care during the growing popularity of the March Madness vasectomy and extending into other major weekend sporting events.

\section{The brosectomy}

Some men find the experience of getting a vasectomy to be too stressful to be done alone. As a means in which to reduce the anxiety, some men are turning vasectomies into social activities with friends, getting the procedure done and recovering together. This "buddy system" of 
getting vasectomies done together has now been coined "the brosectomy". Some men have taken this to a new level as they rent hotel rooms for the weekend and enjoy each other's company in the confines of luxury hotel suites. Urologists have noted that when men undergo a brosectomy, the companionship and support mechanism of having someone else go through the procedure can help mitigate anxiety, and as a result, decrease the need for pain medications, providing another added benefit. The future of men's health includes providing interested patients the opportunity to experience "the brosectomy".

\section{Men's spas}

The amenities offered at spas have generally been tailored towards women-facials, manicures, pedicures, and salon services. However, as spas try to attract men, they offer many of these amenities in a more masculine form. Men's spas are now equipped with comfortable robes and slippers, TVs with Netflix, cappuccino makers, and top-shelf liquor. In 1983, men made up less than $10 \%$ of the US spa market, compared to 2013 when that number jumped to $47 \%$ (29). Spas today are appealing to the demographic of style- and health-conscious men who are more interested in antiaging creams, body cleansing products, and deodorants than previous generations. Skincare lines, traditionally holding products tailored towards women's needs, are now creating male grooming products, as the men's grooming market is projected to grow 5\% annually from 2018 to 2023 (29).

Male grooming is more than just lotions, creams, and shaving creams, as there are now salons specifically tailored towards men. Hammer \& Nails, a grooming spa for men, offers men the opportunity to get a haircut, beard shave, manicure/pedicure, and facial, all while sitting in a classic barber chair, favorite drink in hand, with a sports game on. Just as there are stigmas associated with discussions about ED, many men do not feel comfortable getting manicures and pedicures in salons surrounded by women. But spas like Hammer \& Nails are only increasing in popularity as they are capitalizing on this growing sector.

\section{Diffusion of bealthcare}

Men's health is a broad field that combines various disciplines of medicine to appropriately treat men's health needs throughout the course of a lifetime. In our current state of healthcare, most men's health needs are being treated by physicians of various specialties trying to treat each individual men's health issue. For example, a patient's testosterone replacement is being managed by an endocrinologist at one clinic, while his benign prostatic hyperplasia symptoms are being treated by a primary care doctor on the other side of town, all while he is getting a telemedicine consultation from the Roman's website for his new-onset ED. This diffusion and dilution of men's healthcare, can sometimes lead to poor communication and overall poor patient care.

Although the current diffusion of healthcare has afforded men who would otherwise not get treated for low testosterone and ED some access to appropriate care, it does not always mean the best kind of care. Some of these men who have received telemedicine consultations are offered ED therapy without a full evaluation. In addition, as previously described, some men are going to "low T" centers, only to be offered a small number of potential treatment options. As men's health deepens as a clinical practice, men's health clinics will more often provide comprehensive management of men's endocrine, sexual, physical performance, surgical, and psychological issues.

\section{Conclusions}

Men's health is a unique discipline that should be practiced by physicians comfortable with the urologic, sexual, and reproductive health of men. Since it requires a multidisciplinary approach to appropriately treat the full spectrum of men's health needs, fellowships in men's health are becoming more important. These fellowships cover a broad spectrum of disciplines including andrology, male infertility, and sexual dysfunction. Currently, there are more than 15 available men's health fellowships, including programs at UCLA, Northwestern, Baylor, and the University of Miami, to name a few. Today, men's sexual health education in urologic training is underrepresented, as one study showed that only roughly $50 \%$ of residents received education on proper management of sexual dysfunction during training (30). As men's health as a field continues to grow, the need for fellowships specially designed to cover the men's endocrine, surgical, and psychological needs is becoming increasingly more important. This distinct and evolving field provides men with a full spectrum of care, but requires appropriately trained physicians to cater to their needs.

\section{Acknowledgments}

Funding: None. 


\section{Footnote}

Provenance and Peer Review: This article was commissioned by the Guest Editors (Larry I. Lipshultz, Alexander W. Pastuszak) for the focused issue "Contemporary Issues and Controversies in Men's Health" published in Translational Andrology and Urology. The article was sent for external peer review organized by the Guest Editors and the editorial office.

Conflicts of Interest: The focused issue "Contemporary Issues and Controversies in Men's Health" was commissioned by the editorial office without any funding or sponsorship. The authors have no conflicts of interest to declare.

Ethical Statement: The authors are accountable for all aspects of the work in ensuring that questions related to the accuracy or integrity of any part of the work are appropriately investigated and resolved.

Open Access Statement: This is an Open Access article distributed in accordance with the Creative Commons Attribution-NonCommercial-NoDerivs 4.0 International License (CC BY-NC-ND 4.0), which permits the noncommercial replication and distribution of the article with the strict proviso that no changes or edits are made and the original work is properly cited (including links to both the formal publication through the relevant DOI and the license). See: https://creativecommons.org/licenses/by-ncnd $/ 4.0 \%$.

\section{References}

1. Arias E. United States Life Tables, 2011. Natl Vital Stat Rep 2015;64:1-63.

2. Acciai F, Firebaugh G. Why did life expectancy decline in the United States in 2015? A gender-specific analysis. Soc Sci Med 2017;190:174-80.

3. Population Reference Bureau. Gender disparities in health and mortality. 2007. Available online: https://www.prb.org/ genderdisparities/

4. Baker P. Men's health: an overlooked inequality. Br J Nurs 2016;25:1054-7.

5. Oquendo MA, Kamali M, Ellis SP, et al. Adequacy of antidepressant treatment after discharge and the occurrence of suicidal acts in major depression: a prospective study. Am J Psychiatry 2002;159:1746-51.

6. Ignarro LJ. Nitric oxide: a unique endogenous signaling molecule in vascular biology. Biosci Rep 1999;19:51-71.

7. Inman BA, Sauver JL, Jacobson DJ, et al. A populationbased, longitudinal study of erectile dysfunction and future coronary artery disease. Mayo Clin Proc 2009;84:108-13.

8. Movember Foundation. Movember Foundation Annual Report 2018. 2018; Available online: https://cdn. movember.com/uploads/files/2018/Financials/MovemberFoundation_Annual-Report_US_2018_FA.pdf

9. Schröder FH, Hugosson J, Monique J, et al. Screening and prostate-cancer mortality in a randomized European study. N Engl J Med 2009;360:1320-8.

10. Baillargeon J, Kuo YF, Westra JR, et al. Testosterone Prescribing in the United States, 2002-2016. JAMA 2018;320:200-2.

11. Handelsman DJ. Global trends in testosterone prescribing, 2000-2011: expanding the spectrum of prescription drug misuse. Med J Aust 2013;199:548-51.

12. Low T Center. 2019. Available online: http://lowtcenter. com/low-testosterone-treatment

13. Ho CC, Tan HM. Rise of herbal and traditional medicine in erectile dysfunction management. Curr Urol Rep 2011;12:470-8.

14. Kamatenesi-Mugisha $\mathrm{M}$, Oryem-Origa $\mathrm{H}$. Traditional herbal remedies used in the management of sexual impotence and erectile dysfunction in western Uganda. Afr Health Sci 2005;5:40-9.

15. Cutter CB. Compounded percutaneous testosterone gel: use and effects in hypogonadal men. J Am Board Fam Pract 2001;14:22-32.

16. P\&S Market Research. Telemedicine Market to Cross $\$ 48.8$ Billion by 2023: P\&S Market Research. 2018; Available online: https://www.psmarketresearch.com/ press-release/global-telemedicine-market

17. Ellimoottil C, Skolarus T, Gettman M, et al. Telemedicine in Urology: State of the Art. Urology 2016;94:10-6.

18. Boxer RJ. Telemedicine in a global context. Mhealth 2015;1:12.

19. Accenture. Millennial and Gen $Z$ Consumers Paving the Way for Non-Traditional Care Models, Accenture Study Finds. 2019; Available online: https://newsroom.accenture. com/news/millennial-and-gen-z-consumers-paving-theway-for-non-traditional-care-models-accenture-studyfinds.htm

20. Business Insider. Hot startups like Hims and Roman are marketing Viagra to young men online, but their approach raises 2 big questions. 2019. Available online: https://www.businessinsider.com/hims-and-roman- 
target-erectile-dysfunction-which-can-signal-healthissues-2019-2

21. Yafi FA, Jenkins L, Albersen M, et al. Erectile dysfunction. Nat Rev Dis Primers 2016;2:16003.

22. Frederick LR, Cakir OO, Arora H, et al. Undertreatment of erectile dysfunction: claims analysis of 6.2 million patients. J Sex Med 2014;11:2546-53.

23. Tomlinson J, Wright D. Impact of erectile dysfunction and its subsequent treatment with sildenafil: qualitative study. BMJ 2004;328:1037.

24. Jacobs J. 2019. Available online: https://www.nytimes. com/2019/03/09/science/telemedicine-ethical-issues.html

25. Beck M. How Telemedicine Is Transforming Health Care. Wall Street Journal, June 26, 2016.

26. Wang C, Festin MP, Swerdloff RS. Male Hormonal Contraception: Where Are We Now? Curr Obstet

Cite this article as: Houman JJ, Eleswarapu SV, Mills JN. Current and future trends in men's health clinics. Transl Androl Urol 2020;9(Suppl 2):S116-S122. doi: 10.21037/tau.2019.08.33
Gynecol Rep 2016;5:38-47.

27. Thirumalai A, Swerdloff R, Ceponis J, et al. 239 Pharmacokinetic and pharmacodynamic effects of 28 days of oral dimethandrolone undecanoate in healthy men: a prototype male pill. J Investig Med 2018;66:A165-6.

28. Ostrowski KA, Holt SK, Haynes B, et al. Evaluation of Vasectomy Trends in the United States. Urology 2018;118:76-9.

29. Spa Industry Study 2013. Current Status and Expected Developments. Stenden Rangsit University/Thai Spa Association, 2013.

30. Krouwel EM, Grondhuis P, Putter H, et al. Omissions in Urology Residency Training Regarding Sexual Dysfunction Subsequent to Prostate Cancer Treatment: Identifying a Need. Urology 2016;90:19-25. 